\title{
The prostaglandin challenge Test to unmask obstructed total anomalous pulmonary venous connections in asplenia syndrome
}

\author{
ROBERT M. FREEDOM, PETER M. OLLEY, FLAVIO COCEANI, \\ AND RICHARD D. ROWE \\ From the Division of Paediatric Cardiology and Departments of Paediatrics and Pathology, \\ The Hospital for Sick Children, and Departments of Paediatrics and Pathology, The University \\ of Toronto, Canada
}

The patient with complex congenital heart disease, severe pulmonary outflow tract obstruction, and visceral heterotaxia, may have 'silent' obstruction of the pulmonary venous return. Severe reduction of pulmonary blood flow secondary to pulmonary stenosis or atresia in such patients may prevent the usual radiographic appearance of pulmonary oedema. If such obstructed anomalous pulmonary venous connections are not diagnosed before operation, construction of a systemic to pulmonary artery anastomosis will unmask the obstruction, usually resulting in pulmonary oedema and death. We have recently 'challenged' a neonate with dextrocardia, visceral heterotaxia, presumed asplenia, and complex congenital heart disease including pulmonary atresia, with an infusion of prostaglandin $E_{1}$ to increase pulmonary blood flow via his ductus arteriosus. This resulted in severe pulmonary oedema which partially resolved after the infusion was discontinued. This was interpreted as consistent with obstructed total anomalous pulmonary venous return. This was confirmed at necropsy. Thus, the infusion of prostaglandin $E_{1}$ before operation in the patient with asplenia or similar cardiac disease may be of aid in unmasking 'silent' obstructions of the pulmonary veins, and is of obvious value in the preoperative assessment of such patients.

The neonate with congenital asplenia is usually hypoxic from severe fixed obstruction to pulmonary blood flow (Ivemark, 1955; Putschar and Manion, 1956; Ruttenberg et al., 1964; Rose et al., 1975). All too frequently, construction of a systemic to pulmonary artery anastomosis unmasks 'silent' obstructed total anomalous pulmonary venous connections, which are not uncommon in these patients, resulting in intractable pulmonary oedema and death (Gersony, 1973; Muster et al., 1973).

It is our purpose to comment on the 'prostaglandin' challenge in the preoperative assessment of such patients.

\section{Case report}

This 3-day-old male infant was referred to The Hospital for Sick Children for evaluation of cyanotic congenital heart disease. At birth he weighed $1860 \mathrm{~g}$ and was the product of a pregnancy complicated by premature rupture of the membranes, followed by a spontaneous vaginal delivery. Progressive cyanosis was noted from 18 hours of age, prompting his referral.

Examination at 3 days of age disclosed an infant who was cyanosed, and tachypnoeic to 75 /minute. The pulse was $100 /$ minute, and dextrocardia was evident. The second heart sound was single and loud. No murmurs were audible. The pulses were full. A symmetrical liver could be percussed across the midline. Howell-Jolly bodies were evident in peripheral erythrocytes.

The chest $x$-ray film showed dextrocardia, clear lung fields, and a left aortic arch. The pulmonary blood flow appeared slightly reduced (Fig. 1). The electrocardiogram showed a $\mathrm{P}$ axis of $+120^{\circ}$, and right atrial and right ventricular hypertrophy. Cardiac catheterisation confirmed dextrocardia, bilateral superior vena cava, AP-transposition, pulmonary infundibular atresia, common atrioventricular canal, and either a large ventricular defect or primitive ventricle. Pulmonary venous return 
was never satisfactorily visualised. A persistent ductus arteriosus supplied right and left pulmonary arteries, both moderately hypoplastic.

In order to augment the pulmonary blood flow,

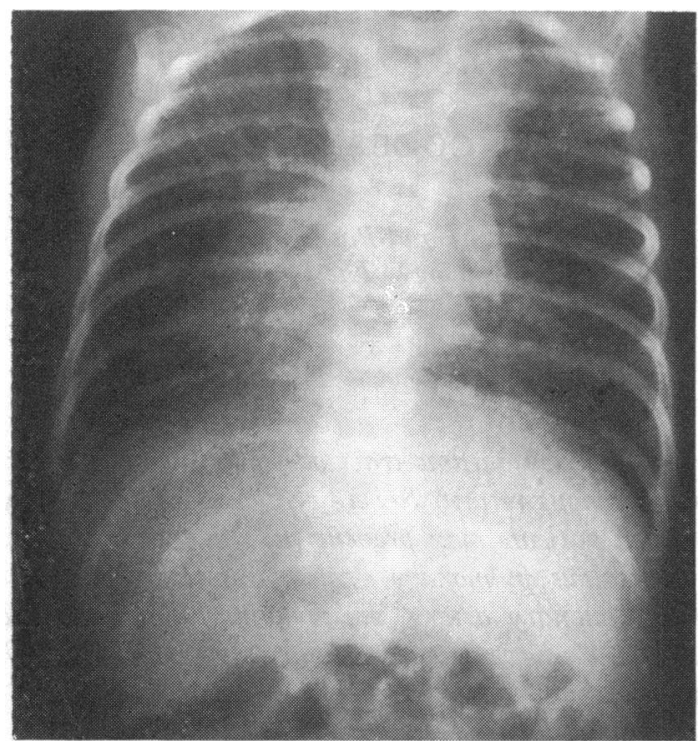

Fig. 1 Chest radiograph on admission. Dextrocardia is present, and liver shadow is abnormally symmetric, consistent with visceral heterotaxia. The central pulmonary vascularity appears normal, but peripherally it seems reduced.

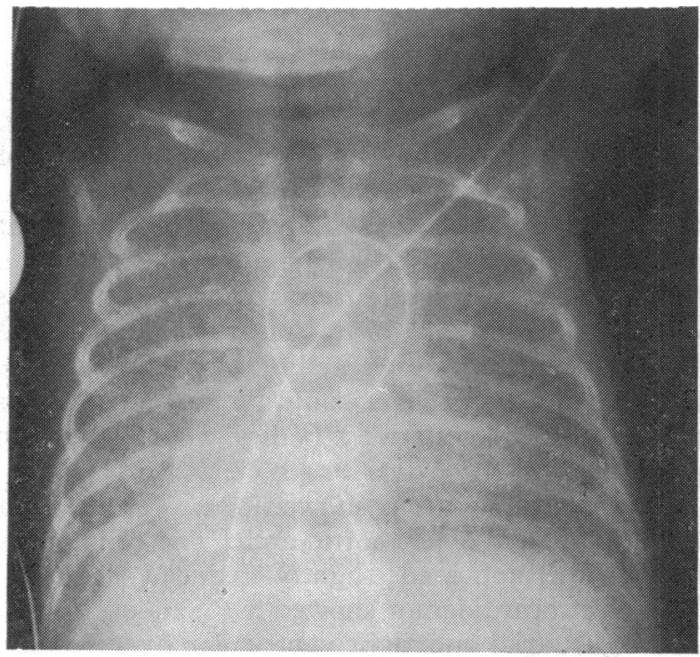

Fig. 2 Chest radiograph taken during prostaglandin infusion. The prostaglandin is administered via the $1 \mathrm{mbilical}$ artery which is positioned in the ascending aorta, proximal to the ductus arteriosus. Pronounced bilateral pulmonary oedema is present. prostaglandin was infused through the umbilical artery cannula at the level of the ductus. Shortly after beginning the infusion, the infant's condition deteriorated, with considerable respiratory distress. The infusion of prostaglandin was discontinued and a second chest $x$-ray film was immediately taken (Fig. 2), which showed severe pulmonary oedema. Several hours later, a third chest radiograph showed considerable clearing of the pulmonary oedema (Fig. 3).

The appearance of pulmonary oedema in response to augmentation of pulmonary blood flow was interpreted as consistent with obstructed total anomalous pulmonary venous return. The baby was not felt to be a candidate for palliation and died at 16 days of age.

Pertinent necropsy findings included dextrocardia, congenital asplenia, visceral heterotaxia, and bilateral eparterial bronchi.

Pertinent cardiac findings included bilateral superior vena cava, atrial inversion, l-ventricular loop with two ventricles, 1-transposition of the great arteries, bilateral conus with pulmonary infundibular atresia, common atrioventricular canal with common atrium, and total anomalous pulmonary venous return to the left superior vena cava with extreme stenosis at the site of communication of the vertical vein with the left superior vena cava. Histological examination of the lungs showed pulmonary oedema with extensive lymphangiectasia (Esterly and Oppenheimer, 1970).

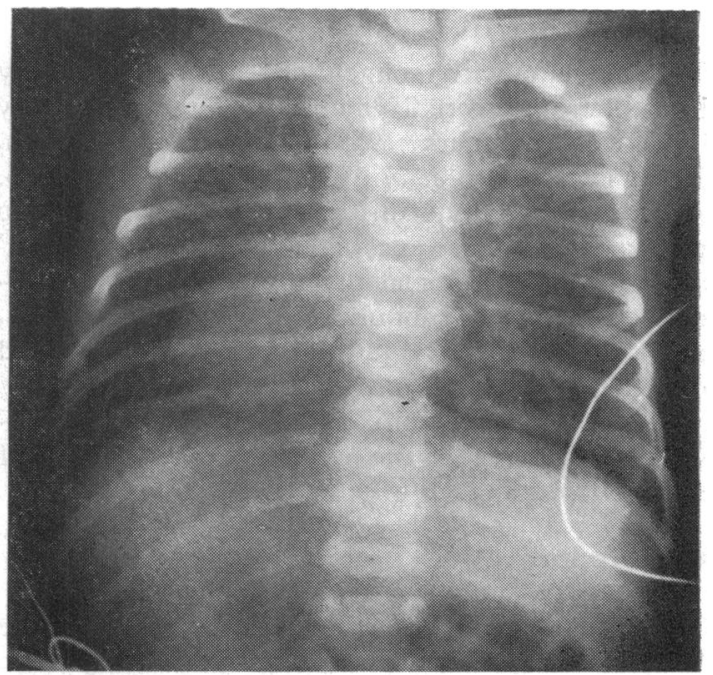

Fig. 3 Subsequent to the discontinuation of the prostaglandin infusion, there is prompt resolution of the intense pulmonary oedema. 


\section{Discussion}

Certain congenital heart defects with severe obstruction to pulmonary blood flow are almost entirely dependent on persistence of the ductus arteriosus for the maintenance of pulmonary blood flow. In those hypoxic neonates with critical pulmonary outflow tract obstruction to whom prostaglandin $\mathrm{E}_{1}$ has been administered, an immediate and persistent rise in arterial oxygen saturation has been produced. From the observations of Olley and his colleagues, this change can be ascribed to dilatation of the ductus arteriosus, with subsequent augmentation of pulmonary blood flow (Coceani and Olley, 1973; Coceani et al., 1975; Olley et al., 1975, 1976).

It is well known that critical pulmonary outflow tract obstruction and anomalous pulmonary venous connections are just part of the constellation of the complex cardiac malformations intrinsic to the congenital asplenia syndrome (Ivemark, 1955). Recently, Delisle and his colleagues (1976) have reported that anomalous pulmonary venous connections are obstructed in 48 per cent of patients with heterotaxia and total anomalous pulmonary venous return. In such patients with obstructed total anomalous pulmonary venous return and critical pulmonary outflow tract obstruction, the pulmonary venous obstruction may be 'silent', that is, it may be masked by severe restriction of pulmonary blood flow. If pulmonary blood flow is augmented, either by the infusion of prostaglandin as in the present case, or by construction of a systemic to pulmonary artery anastomosis, the obstructed anomalous pulmonary venous connections may be unmasked (Gersony, 1973; Muster et al., 1973).

The use of prostaglandin to unmask the pulmonary venous obstruction has certain attractive features in these patients. It is most unlikely that the neonate with severe pulmonary outflow tract obstruction would develop pulmonary oedema on the basis of increased ductal flow alone. However, if pulmonary congestion occurred after creation of a systemic to pulmonary artery anastomosis, the congestion could be attributed to either too large a shunt and/or obstructed pulmonary venous connections. Furthermore, the prostaglandin effect is rapidly reversible by stopping the infusion. At present, it is uncertain as to at what age the ductus arterious remains responsive to prostaglandin $E_{1}$. Certainly, it is most efficacious in the newborn. In addition, we cannot be certain that failure to produce pulmonary oedema excludes mildly obstructed total anomalous pulmonary venous connections.
We believe that the patient with asplenia syndrome deserves a thorough cardiac examination, including catheterisation and angiocardiography. If the pulmonary venous drainage is not clearly defined by this study, then we would suggest the intra-arterial administration of E-type prostaglandin as a test to unmask obstructed pulmonary venous connections (indeed, as an adjunct to cardiac catheterisation). If pulmonary oedema develops during prostaglandin administration in such a patient with complex congenital heart disease, and severe fixed obstruction to pulmonary blood flow, we would interpret this as evidence of obstructed pulmonary venous connections. This patient would probably not be considered a candidate for palliative surgery to augment pulmonary blood flow. Similarly, if a patient had obstructed total anomalous pulmonary venous connections (i.e. infradiaphragmatic, azygos, etc. communications) documented at cardiac catheterisation, we would nat recommend infusion of E-type prostaglandin to augment pulmonary blood flow. Indeed, though the pulmonary blood flow would increase, one would expect a corresponding increment in pulmonary venous pressure, with resulting pulmonary oedema and death.

Although the patient with congenital asplenia usually has extremely severe, and life-threatening cardiac malformations, some of these patients can be significantly benefited by augmentation of pulmonary blood flow (despite earlier proclamation that these patients are inoperable) (Lucas et al., 1962; Roberts et al., 1962). Certainly, reports of successful total repair of the complicated cardiac anomalies associated with asplenia should speak for the need for a thoughtful and thorough evaluation of each of these patients (Ando et al., 1976).

\section{References}

Ando, F., Shirotani, H., Kawai, J., Kanzaki, Y., Setsuie, N., Yamaguchi, K., Okamoto, F., Yokoyama, T., Makino, S., Tateishi, K., and Nishi, K. (1976). Successful total repair of complicated cardiac anomalies with asplenia syndrome. Fournal of Thoracic and Cardiovascular Surgery, 72, 33-38. Coceani, F., and Olley, P. M. (1973). The response of the ductus arteriosus to prostaglandins. Canadian fournal of Physiology and Pharmacology, 51, 220-225.

Coceani, F., Olley, P. M., and Bodach, E. (1975). Lamb ductus arteriosus: effect of prostaglandin synthesis inhibitors on the muscle tone and the response to prostaglandin $\mathrm{E}_{2}$. Prostaglandins, 9, 299-308.

Delisle, G., Ando, M., Calder, A. L., Zuberbuhler, J. R., Rochenmacher, S., Alday, L. E., Mangini, O., Van Praagh, S., and Van Praagh, R. (1976). Total anomalous pulmonary venous connection: report of 93 autopsied cases with emphasis on diagnostic and surgical considerations. American Heart fournal, 91, 99-122.

Esterly, J. R., and Oppenheimer, E. H. (1970). Lymphangiectasis and other pulmonary lesions in the asplenia syndrome. Archives of Pathology, 90, 553-560. 
Gersony, W. M. (1973). Obstruction to pulmonary venous return obscured by decreased pulmonary blood flow. Chest, 64, 283.

Ivemark, B. (1955). Implications of agenesis of the spleen on the pathogenesis of conotruncal anomalies in childhood. Acta Paediatrica, Suppl. 104

Lucas, R. V., Jr., Neufeld, H. N., Lester, R. G., and Edwards, J. E. (1962). The symmetrical liver as a roentgen sign of asplenia. Circulation, 25, 973-975.

Muster, A. J., Paul, M. H., and Nikaidoh, H. (1973). Tetralogy of Fallot associated with total anomalous pulmonary venous drainage. Chest, 64, 323-326.

Olley, P. M., Bodach, E., Heaton, J., and Coceani, F. (1975). Further evidence implicating E-type prostaglandins in the patency of the lamb ductus arteriosus. European fournal of Pharmacology, 34, 247-250.

Olley, P. M., Coceani, F., and Bodach, E. (1976). E-type prostaglandins. A new emergency therapy for certain cyanotic congenital heart malformations. Circulation, $53,728-731$.
Putschar, W. G. J., and Manion, W. C. (1956). Congenital absence of the spleen and associated anomalies. American Fournal of Clinical Pathology, 26, 429-470.

Roberts, W. C., Berry, W. B., and Morrow, A. G. (1962). The significance of asplenia in the recognition of inoperable congenital heart disease. Circulation, 26, 1251-1253.

Rose, V., Izukawa, T., and Moës, C. A. F. (1975). Syndrome of asplenia and polysplenia. British Heart fournal, 37, 840-852.

Ruttenberg, H. D., Neufeld, H. N., Lucas, R. V., Jr., Carey, L. S., Adams, P., Jr., Anderson, R. C., and Edwards, J. E. (1964). Syndrome of congenital cardiac disease with asplenia: distinction from other forms of congenital cyanotic cardiac disease. American fournal of Cardiology, $13,387-406$.

Requests for reprints to Dr. Robert M. Freedom, The Hospital for Sick Children, 555 University Avenue, Toronto, Ontario, Canada M5G 1 X8. 